Boise State University

ScholarWorks

$1-1-2006$

Seeing Through the Noise: Seismic Reflection Profiling in Urban Areas

Lee M. Liberty

Boise State University

Thomas L. Pratt

U.S. Geological Survey

Scott S. Hess

Boise State University 


\title{
SEEING THROUGH THE NOISE: SEISMIC REFLECTION PROFILING IN URBAN AREAS
}

\author{
Lee M. Liberty, Boise State University, Boise, ID \\ Thomas L. Pratt, U.S. Geological Survey, Seattle, WA \\ Scott S. Hess, Boise State University, Boise, ID
}

\begin{abstract}
Studies for urban hazard or resource assessment often take place in densely populated areas characterized by considerable cultural noise. These site conditions can severely compromise seismic reflection data quality. We have collected vibroseis and hammer (weight drop) seismic reflection data in a range of geologic conditions to image stratigraphy and structures in the upper one $\mathrm{km}$ along regional highways, city streets, and power line access roads. In addition to the challenges of safety and outreach, acquisition efforts along busy streets and highways often encounter poor receiver coupling and largeamplitude coherent noise from traffic and power lines. Although higher quality seismic reflection data may be obtained by simply choosing alternate sites with less cultural noise, modifications to the acquisition and processing steps can minimize the effects of cultural noise and poor coupling where profiling is most relevant. Flagging crews, flyers and public announcements assist with outreach and safety concerns, and the local news media are often enthusiastic about publicizing geologic studies. Recording long-record vibroseis data reduces the effects of noise by itself, but data quality can be further optimized by recording uncorrelated, unstacked data and applying precorrelation amplitude adjustments and filters. Recording individual hammer shots likewise allows gains or mutes to normalize or remove traffic noise prior to vertical stacking. Large numbers of receiver channels allow attenuation of random noise and velocity filtering to remove coherent noise. Because ground roll and normal moveout (NMO) corrections minimize near-surface coverage, asymmetric source-receiver geometry allows for additional near-surface fold while muting large amplitude ground roll and NMO stretch. Source and geophone coupling on road shoulders can degrade signal quality due to variable materials and topography, but these problems are often addressed with static corrections. Our experience is that high-quality seismic data can be obtained in noisy urban areas, but many recorded channels and a careful attention to acquisition and processing procedures can significantly improve the results.
\end{abstract}

\section{Introduction}

There is no better non-invasive tool for characterizing geologic structures and stratigraphy than reflection imaging. Seismic reflection methods are ideally suited for groundwater, hazard, and other geologic studies because acoustic velocity and density contrasts in the upper one km often define key geologic horizons. To obtain reflections from these key horizons, seismic sources and receivers must be deployed where returned reflected seismic signals exceed background noises and source/receiver separations approach imaging depths. The most pressing geologic problems that affect large populations often must be addressed in heavily populated regions where cultural noise and permitting obstacles are present. These regions may have traffic noise, electrical noise from power lines, buried utilities, concrete and asphalt surfaces, and artificial surface fill. To obtain regional two-dimensional subsurface images, restricted roadways and multiple property boundaries are often encountered when siting profiles. For the 
past few years, we have conducted a number of seismic reflection surveys in heavily populated areas along busy highways, residential roads, city parks, and railroad lines. We have used both vibroseis and hammer seismic sources to obtain images of structures and stratigraphy of sedimentary and volcanic rocks in the upper one $\mathrm{km}$. Here we present the steps we have taken to produce high quality data through urban corridors. We believe safety, outreach, and line locations are as critical as acquisition and processing parameters, therefore we begin with a discussion on planning and permitting issues. We then describe our acquisition and processing steps and compare our data to marine profiles. We conclude that high fold data and careful attention to processing steps can significantly improve the final stack.

\section{Planning and Permitting}

Prior to conducting regional seismic reflection surveys in urban areas, we must obtain permits from municipalities and private entities. Permitting can pose a challenge because many institutions, especially private companies that have no stake in the seismic results, lean toward a very conservative approach to property access. Concerns regarding liabilities, noise concerns of neighbors, property damage from seismic sources and vehicles, and implications for identifying site hazards often are disincentives for access. Concessions, time restrictions, and profile relocations may result from the permit process. Generally, the larger the institution and the more urbanized the location, the greater the challenge in permitting. Be prepared for personal visits and pleas; provide descriptions of acquisition methodologies, anticipated results, and implications of your findings. Media coverage and one-page fact sheets often assist in gaining local support and disseminating project information.

The benefits to working in urban areas are the common availability of well information, high resolution light detection and ranging (lidar) topography, detailed aerial photos, and nearby stores for supplies. Road cuts often provide exposures in densely vegetated areas, and generally there is broad interest and support from residents and businesses as to the methodologies and results. To satisfy some permits and improve safety and signal quality, we have employed certified flagging crews. These professionals will slow traffic (an added benefit to seismic results), and ensure the safety of pedestrians, motorists, and the seismic crew. They also allow the seismic crew to operate seismic equipment without distraction along busy roads (Figure 1).

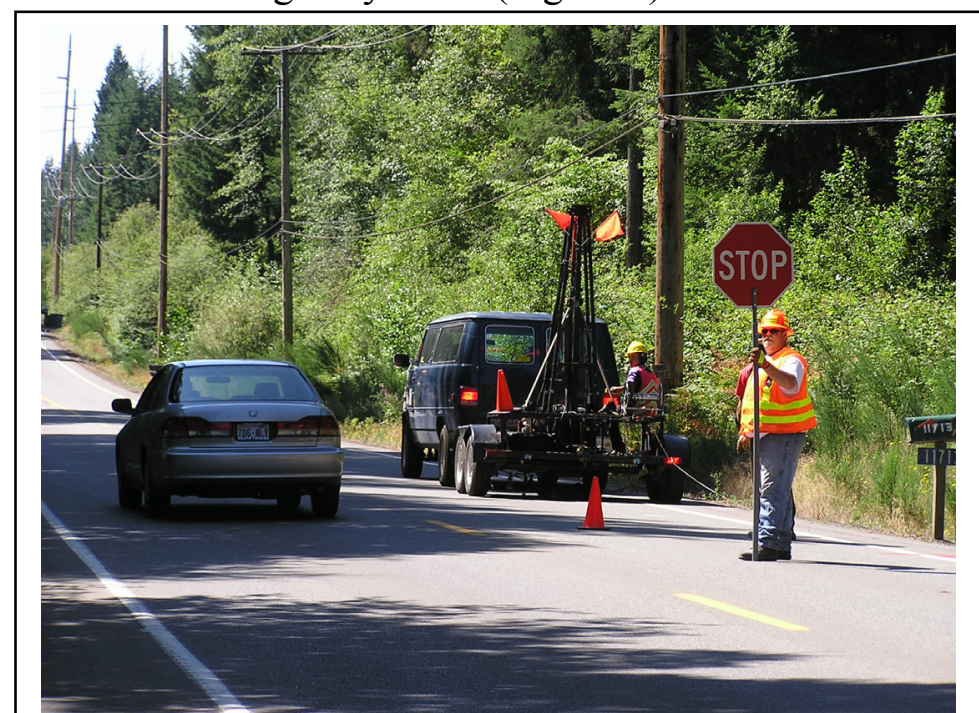

Figure 1. Trailer-mounted hammer source in operation across the Tacoma fault in northwest Washington State with a certified flagger controlling traffic. This source provided images to $1.4 \mathrm{~s}$ two-way travel time along a $45 \mathrm{mph}$ road with continuous car and truck traffic. Geophones were planted along the right road shoulder.
We collected a number of hammer and vibroseis seismic reflection profiles throughout the Pacific Northwest over the past few years. We have operated both seismic sources along residential streets and regional highways, through parks, and along railroad access roads with minimal road impact, no accidents or injuries, and produced high quality results that have improved and modified our understanding of geologic and tectonic infrastructure related to aquifer and hazard assessments.

\section{Seismic Data Acquisition}

We will focus our discussion on two projects from the Puget Lowlands collected from 2004-2005, one dataset collected with 
a vibroseis source and the other collected with a trailer-mounted hammer (accelerated weight drop) seismic source. Both surveys were conducted with similar cultural conditions along residential streets, highways, and power line access roads and had similar geologic conditions and target objectives. Both surveys progressed from a basin to an adjacent uplift across active faults. We used $10 \mathrm{~Hz}$ vertical geophones for both experiments. P-wave seismic velocities for latest Pleistocene and Holocene strata average $1600 \mathrm{~m} / \mathrm{s}$ when saturated and $1200 \mathrm{~m} / \mathrm{s}$ when unsaturated. Pleistocene strata average $2000 \mathrm{~m} / \mathrm{s}$. Miocene and older sediments within the uplift and below Quaternary fill measure upwards of $2800 \mathrm{~m} / \mathrm{s}$. Glacial till that appears in outcrop throughout the region and is likely contained within the upper few hundred meters, has measured seismic velocities up to $2500 \mathrm{~m} / \mathrm{s}$. Our surveys were conducted near marine airgun seismic profiles that provide a comparison between marine and land seismic methods and results.

Both seismic datasets relied upon lidar topographic data and detailed aerial photos to identify source and receiver locations. We collected GPS data with a handheld GPS unit, labeled our positions on detailed aerial photos (e.g., street corners), rectified our GPS positions with ArcGIS software, and extracted elevation values from the lidar database. Assuming we spatially locate our coordinates correctly, we obtain cm level accuracy for our elevation measurements with this method.

\section{Vibroseis}

In June, 2004, we collected more than $20 \mathrm{~km}$ of seismic reflection data across the Seattle fault zone in Bellevue, Wa, with a 12,000 lb IVI minivib II vibroseis truck (Figure 2). Our surveys were along mostly residential streets using a $12 \mathrm{~s}, 20-160 \mathrm{~Hz}$ linear sweep. We recorded an additional $2 \mathrm{~s}$ to obtain 14 s shot gathers. We acquired off-end data with a 120-channel, 24-bit Geometrics RX seismograph (60channel master and slave). We used 5-m source and receiver intervals to produce nominal 60 -fold data with offsets up to $600 \mathrm{~m}$. We recorded uncorrelated, individual field records to employ pre-correlation

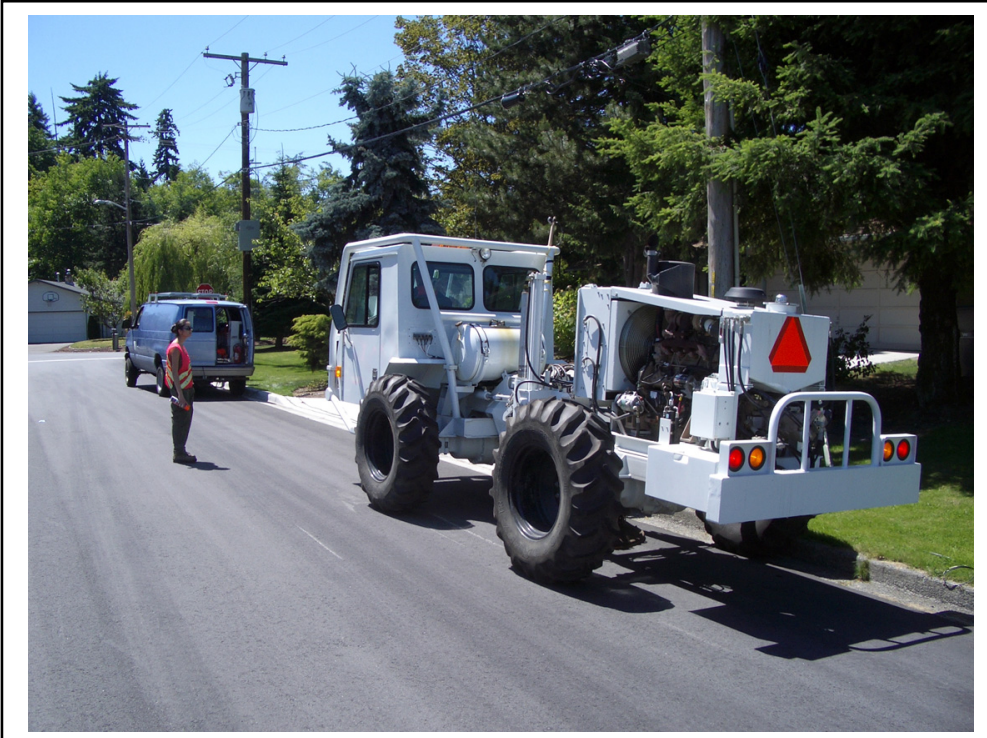

Figure 2. Vibroseis seismic source and recording truck in Bellevue, WA along a residential street. Geophones were placed along the adjacent lawns and driveways. processing to attenuate cultural noise. We swept 2-4 times per location. Maximum reflection depths varied depending on surface conditions (e.g., source and receiver coupling, ground roll), depth to saturated sediments, and geologic structural setting. Objectives were to image the upper one $\mathrm{km}$ of the Seattle Basin and Seattle Uplift across two northsouth transects located east of Puget Sound and Lake Washington. Both waterways have published marine seismic reflection data to compare with our land seismic results (e.g., Johnson et al., 1999; Calvert et al., 2003).

We have found that acquisition on city streets provides excellent signal quality, even with the presence of significant traffic noise. The presence of

large power lines introduces substantial noise into the gathers and results in a loss of returned signals from deeper horizons. We also found poor coupling on soft surfaces with the vibroseis source. This poor coupling resulted in limited reflections from deeper targets. Therefore, city streets and highways provided the best signal quality while using the vibroseis source. We observed no damage as a result of plate coupling, but residents disliked the noise and vibrations that the swept source generated. One 
disadvantage to recording uncorrelated data is that real time quality control is compromised. We randomly correlated gathers in the field to check field records, but identifying reflections and cultural noise in the field was difficult because we were collecting unstacked shot records.

\section{Hammer}

During July, 2005, we collected seismic reflection data with a rubber-band-accelerated, 550-1b hammer source (Figure 1). We shot into a 180-channel spread and recorded the data with three Geometrics 24-bit, 60-channel RX seismographs. We collected data using 5-m source and receiver spacing and asymmetric split-spread geometry to produce 60 to 90 fold data. We stacked 4 times per location, but did not stack common shot gathers in the field. The objectives were to image the upper one $\mathrm{km}$ of the Tacoma Basin and Seattle Uplift across three north-south profiles. These profiles were located in southern Puget Sound, within Case and Carr Inlets. Published seismic data from these waterways (Pratt et al., 1997; Johnson et al., 2004) provide an opportunity to compare our land seismic methods and results to nearby marine profiles.

A major concern with using a large hammer on city streets was the potential for road damage. We found that on most roads, little or no damage appeared from this source when the hammer struck a large steel plate $\left(1 \mathrm{~m}^{2}\right)$ on the road. However, on unimproved roads and road shoulders, cracks on asphalt and concrete edges occasionally resulted. We opted to block a portion of one lane of traffic where possible because we found improved coupling and a decrease in road damage when striking the more solid sections of the roads. On dirt roads, the reflection signal from the hammer source improves after a few hits of the hammer to compact the near surface. By recording unstacked field records, we are able to examine the effects on signal quality from individual hammer blows, discriminating as necessary to improve our stack. One method to compare source coupling is to produce a stack with only the first hammer blow per location and another with only the last hammer blow per location. Source coupling as a function of surface material and compaction should be evident and appropriate edits can follow.

\section{Seismic Data Processing}

\section{Vibroseis}

We recorded uncorrelated, unstacked vibroseis data to attenuate and identify cultural noise prior to correlation. By prefiltering and gain-adjusting the uncorrelated records, we reduced traffic noise and electrical noise associated with power lines. We did not combine individual shot records prior to midpoint sorting and processing, as this allows us to utilize residual statics routines to address small timing errors from radio triggers. Changing source conditions between shots acquired on uncompacted road shoulders and dirt roads also contributed to timing errors and changing signal quality. Although we generated significantly larger data files by recording unstacked and uncorrelated data, modern computing power requires little extra processing time to generate a stack. We discarded amplitude information by gain-adjusting shot records prior to stack, but we found improved results by normalizing prestack gathers to attenuate non-repeatable coherent noise.

Figure 3 shows vibroseis shot records from both the Seattle Basin and the Seattle Uplift (Pratt and others, 1997). Shot A from the Seattle Basin shows reflections in the upper $1000 \mathrm{~ms}$ or $800 \mathrm{~m}$ depth. Strong reflectors from deeper in the section cut through ground roll and matched the top of the Tertiary section in adjacent Lake Washington (Johnson et al, 1999; Figure 3). Shot B was acquired on the Seattle Uplift where Tertiary marine and non-marine sediments appear. 
A)
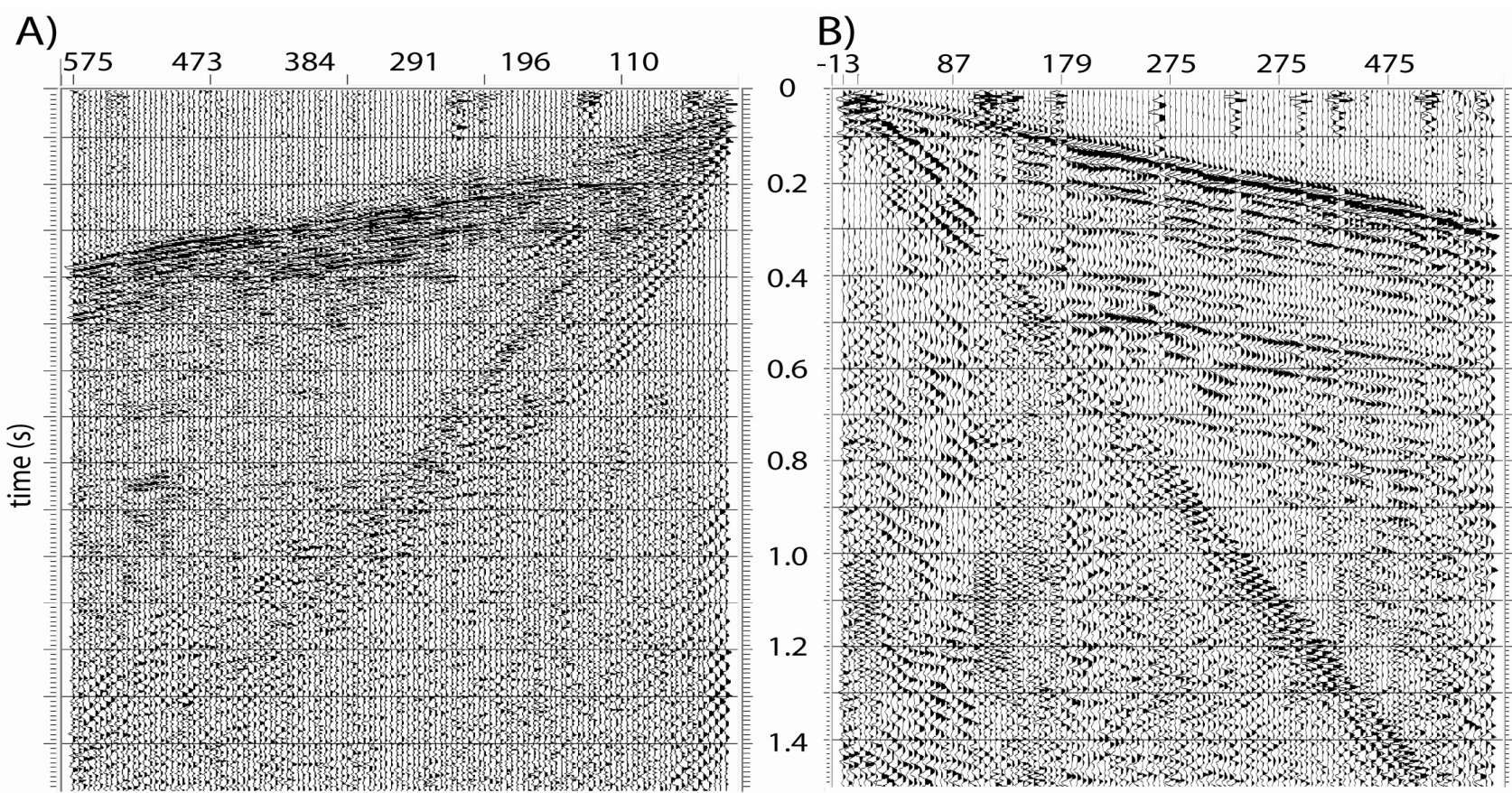

Figure 3. Vibroseis shot gathers from Bellevue, WA. (A) Profile BV2 shot gather showing reflections from Quaternary sediments within the Seattle Basin, (B) Profile BV4 shot gather showing reflections from tilted Tertiary marine sediments on the Seattle Uplift. Distances are labeled across the top in meters.

Figure 4 shows stacked sections from the Seattle Basin and Seattle Uplift. We observe reflections with a peak frequency of $40 \mathrm{~Hz}$. This is comparable in frequency to marine profiles from Puget Sound and Lake Washington (Johnson et al., 1999; Calvert et al., 2003). We observe high quality reflections from Quaternary marine and non marine sediments, Tertiary marine sediments, and Eocene volcanic rocks. By mapping these boundaries, we can constrain the timing and character of deformation. Also, because glaciers scoured the waterways to over $100 \mathrm{~m}$ depth and post-glacial sediments have partially filled the waterways, we can more reliably interpret late Quaternary motion on the Seattle fault by imaging the thick glacial strata with land profiles. Using land seismic methods, we can observe deformation to within a few meters of the surface, providing a tie to paleoseismic trenches. Because the
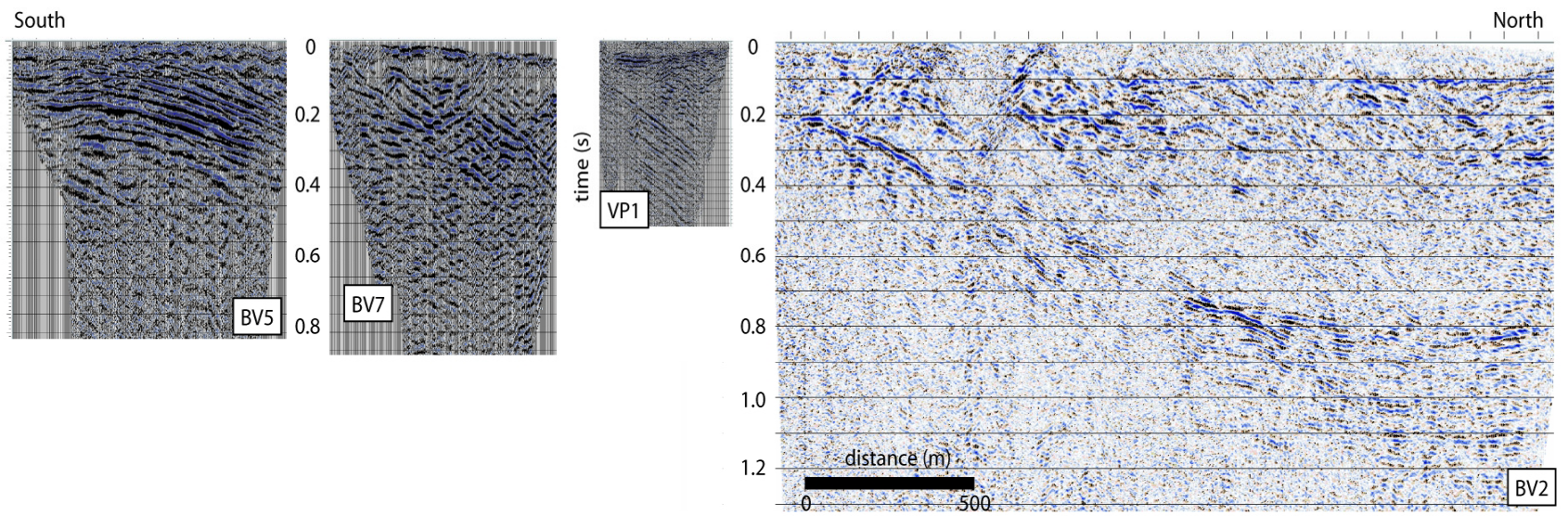

Figure 4. Vibroseis profiles from the Seattle Uplift (left) and Seattle Basin (right). BV5, BV7, and VP1 show north-dipping, folded, and faulted Tertiary sediments in the upper $500 \mathrm{~m}(600 \mathrm{~ms}$ twtt). BV2 from the Seattle Basin shows reflections to more than $1200 \mathrm{~ms}(1 \mathrm{~km}$ depth). The change in reflector pattern to the north at 800 ms represents a transition from Quaternary marine and nonmarine sediments to Tertiary marine sediments. 
Seattle fault extends laterally for more than $70 \mathrm{~km}$ (e.g., Blakely et al., 2002), we can acquire land seismic data to map the limits of the Seattle fault beyond the extent of the regional waterways.

\section{Hammer}

Hammer data acquired across the Tacoma fault show clear reflections to a depth of $1.4 \mathrm{~s}$ twtt. We recorded $2 \mathrm{~s}$ field records. Unstacked field records provided improved signal quality over vertically stacked data, especially where high traffic areas, power lines, and soft surface conditions affected trigger timing and signal quality. In some instances, a double bounce by the hammer appeared in the raw shot records. This second source hit was not a factor due to the following; 1) the amplitude of the second bounce was significantly smaller than the primary hit; 2) the semi-random nature of the second bounce coupled with velocity disparities (the $2^{\text {nd }}$ bounce contained a 200-500 ms delay); and 3 ) attenuation due to high fold data coupled with CMP sorting, normal moveout velocity corrections, and stacking.

Because we acquired high fold data in a structurally complex area, advanced signal processing steps were critical for generating high quality stacks. Detailed velocity analyses, including prestack migration, improved our results and confidence in interpretations. Refraction tomography is also possible with these data due to the acquisition geometry and high quality head-wave arrivals.

One objective of our land-based seismic surveys was to extend interpretations from nearby marine profiles. Figure 5 shows both marine and land stacked sections from the Tacoma Basin and the Seattle Uplift. The marine stack shows tilted Quaternary and older sediments of the Tacoma Basin. The adjacent stack from land shows the same package of reflections dipping to the south. Both marine and land seismic data show clear reflections to more than $1 \mathrm{~s}$ or approximately $1 \mathrm{~km}$ depth. Seismic character allows us to interpret the base of the Quaternary sediments and the top of the Eocene volcanic rock sequence. Both marine and land seismic data also have identified deformation associated with the Tacoma fault. Thus, we consider both seismic methods as equally valuable in interpreting geologic structures. One benefit to the marine data is the very fast acquisition and relatively simple processing involved with low fold data. One benefit to the land data is the freedom to choose line locations to cross structures of interest. However, a $10 \mathrm{~km}$ marine profile takes a few hours to collect, whereas it took approximately 5 days to collect $10 \mathrm{~km}$ of land data.

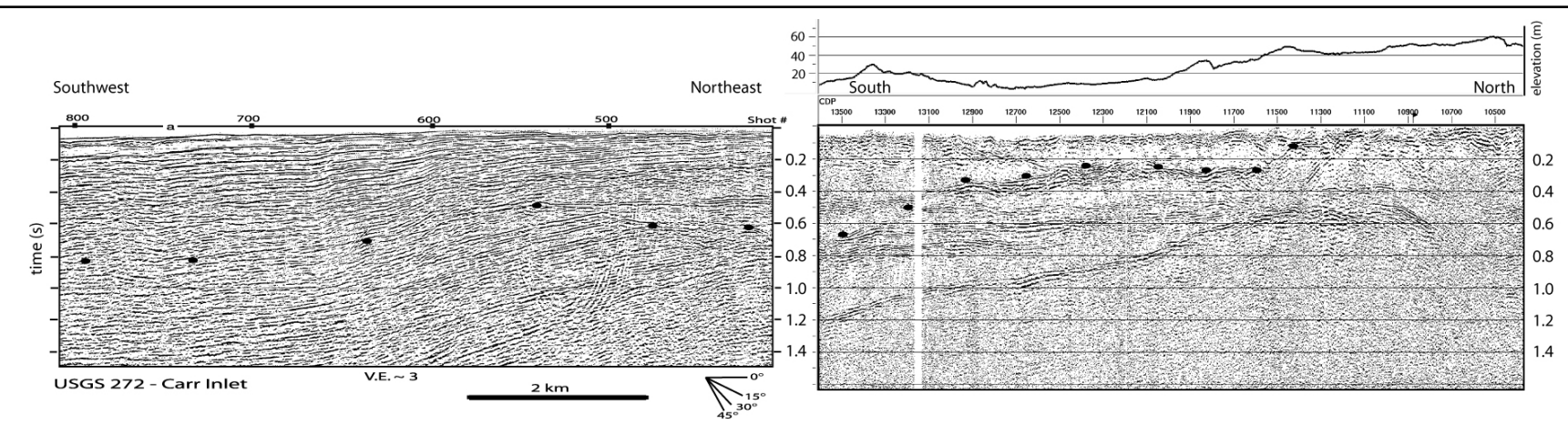

Figure 5. Airgun marine (left) and hammer land (right) stacks across the Tacoma fault zone. South-dipping marine sediments and volcanic rocks appear in both sections to a depth of approximately $1.2 \mathrm{~km}(1.4 \mathrm{~s}$ twtt). Dotted line indicates base of Quaternary. Marine data from Johnson et al. (2004).

\section{Conclusions}

Seismic reflection surveying on land within the Puget Lowland has produced high quality images, comparable to marine profiling, at a relatively low cost. Although the time required to acquire 
marine data is significantly less than an equivalent land line, additional geologic objectives are attainable on land, especially in the Puget Sound area. Significant time must be spent prior to land acquisition for permitting and public outreach. It is important to connect with local geologists, municipal planners, and residents who are impacted by the seismic acquisition and interpretations. Beyond permitting and outreach, we find the key to seismic imaging in urban areas is high fold data with minimal field processing. We rely on the large datasets to be reduced during processing. This procedure allows us to account for expected and unexpected sources of noise and anomalies in the data. Unstacked field data also allow correction of timing errors from changing surface conditions and trigger errors, reduction of large amplitude cultural noise on raw field gathers, and the ability to discriminate shot data. Detailed processing from high fold data allows velocity filtering to remove additional sources of coherent noise. Advanced methods that include prestack migration and refraction tomography allow us to image and interpret complex structures and unravel the tectonic history of this region.

\section{References}

Blakely, R. J., R. E. Wells, C. S. Weaver, and S. Y. Johnson, 2002, Location, structure, and seismicity of the Seattle fault, Washington, U.S. Geol. Soc. Am. Bull., 114, 169-177.

Calvert, A.J., Fisher, M. A. Johnson, S. Y., Brocher, T. M., Creager, K. C., Crosson, R. S., Hyndman, R. D., Miller, K. C., Mosher, D. C., Parsons, T., Pratt, T. L., Spence, G. D., ten Brink, U. S., Trehu, A. M.; Weaver, C. S., 2003, Along-strike variations in the shallow seismic velocity structure of the Seattle fault zone; evidence for fault segmentation beneath Puget Sound, Journal of Geophysical Research,108, no. B1, 20030110.

Johnson, S.Y., R.J. Blakely, W.J. Stephenson, S.V. Dadisman, and M.A. Fisher, 2004, Active shortening of the Cascadia forearc and implications for seismic hazards of the Puget Lowland, Tectonics 23, TC1011, doi:10.1029/2003TC001507.

Johnson, S. Y., S. V. Dadisman, J. R. Childs, and W. D. Stanley, 1999, Active tectonics of the Seattle fault and central Puget Lowland: Implications for earthquake hazards, Geol. Soc. Am. Bull., 111, $1042-1053$.

Pratt, T. L., S. Y. Johnson, C. J. Potter, and W. J. Stephenson, 1997, Seismic reflection images beneath Puget Sound, western Washington State: The Puget Lowland thrust sheet hypothesis, J. Geophys. Res., 102, 27,469 - 27,490. 